\title{
Variation in epiretinal membrane components with clinical duration of the proliferative tissue
}

\author{
I Morino, P Hiscott, N McKechnie, I Grierson
}

\begin{abstract}
Immunohistochemical investigations were conducted on surgically excised epiretinal membranes to determine how cellular and extracellular components of proliferative vitreoretinopathy membranes change with time. Specimens of less than four months' duration contained a significantly higher proportion of retinal pigment epithelial cells than later membranes. No association was found between membrane duration and the content of collagen subtypes I to IV and laminin, but 'early' specimens contained significantly more fibronectin than did 'late' membranes. Fibronectin and collagens I, III, and IV showed a variable relationship with glial cells and were most consistently associated with retinal pigment epithelial and fibroblastlike cells. These observations may explain some of the surgical features of epiretinal membranes.
\end{abstract}

Epiretinal membranes (ERMs) are fibrocellular proliferations on the retinal surface whose content depends on several factors including aetiology and clinical duration. Thus ERMs complicating rhegmatogenous retinal detachment - that is, proliferative vitreoretinopathy (PVR) membranes - contain retinal pigment epithelial (RPE) cells, while membranes arising in the absence of a retinal hole tend to lack RPE. ${ }^{1}$ Furthermore, long standing ERMs contain more collagen but fewer cells than membranes of short clinical duration. ${ }^{23}$ Although the association between clinical duration and ERM fibrosis is reminiscent of the scarring process in the skin, unlike dermal wounds ${ }^{4}$ little is known about the effect of aging on specific cellular or extracellular ERM elements.

To determine how subcomponents of ERMs change with time we have undertaken an immunohistochemical study of (1) various subpopulations of cells (including glia and RPE) and extracellular matrix constituents (collagen types I to IV and the glycoproteins fibronectin and laminin) in surgically excised specimens, and (2) a correlation between the cellular and extracellular components of the membranes. We restricted this investigation to PVR membranes (to minimise the effects of aetiological factors on membrane content).

Pathology, Institute of Ophthalmology, London I Morino

P Hiscott

N McKechnie

I Grierson

Correspondence to:
Paul Hiscott, Department of

Paul Hiscott, Departmentogy, Institute of

Pathology, Institute of

Ophthalmology, 17-25 Cayto

Accepted for publication

2 February 1990
Twenty ERMs were obtained during closed pars plana microsurgery for PVR (grade $\mathrm{Cl}$ or worse ${ }^{5}$ ). The ERMs were arbitrarily grouped into those of less than four months' duration (early ERMs) and those over four months' duration (late ERMs)
Specimens were processed for immunohistochemistry as previously described. ${ }^{36-8}$ Serial sections were cut right through the specimens and immunostained sequentially with a panel of monoclonal antibodies and polyclonal antisera to the following cellular intermediate filaments or extracellular matrix components:

(i) glial fibrillary acidic protein (GFAP) - a glial cell marker (mouse monoclonal anti-GFAP, ICN Biomedical);

(ii) cytokeratins - an epithelial marker (mouse monoclonal antibodies, NCL 5D3 EuroDiagnostics and $\mathrm{K}_{\mathrm{G}} 8 \cdot 13$ SIGMA);

(iii) collagen type I - interstitial collagen also found in maturing scars (goat antiserum, Southern Biotechnology Associates);

(iv) collagen type II - the collagen of the vitreous (goat antiserum, Southern Biotechnology Associates);

(v) collagen type III - interstitial collagen also found in early scars (goat antiserum, Southern Biotechnology Associates);

(vi) collagen type IV - a component of basement membranes (goat antiserum, Southern Biotechnology Associates);

(vii) fibronectin - a glycoprotein which has important roles in healing wounds (rabbit antiserum, DAKOPATTS);

(viii) laminin - a glycoprotein fraction of basement membranes (rat monoclonal antibody, ICN Biomedical).

Where the specimens were too small to provide sufficient sections for all the immunostaining procedures, the specimen was discarded from the study.

Appropriate positive and negative controls were applied to all procedures. ${ }^{367}$ In addition some sections were stained with haematoxylin and eosin. The preparations were examined by bright field, differential interference contrast, and epifluorescence microscopy.

The percentage of cells staining positively for GFAP and cytokeratin together with the proportion of the tissue staining for collagen types I to IV, fibronectin and laminin was recorded for each specimen (this semiquantitative assessment was made by three observers independantly and the results subsequently averaged). ${ }^{37}$ For statistical comparisons between early and late ERMs the Mann-Whitney $U$ test was adopted (level of significance taken as $p<0.05$ ).

Relationships between the cellular and extracellular components of the specimens were recorded from comparisons of immunostained sequential ERM sections. Both intra- and extracellular collagens and glycoproteins may show immunoreactivity, ${ }^{39}$ but we did not attempt to quantitate immunolabelling at either of these sites. 


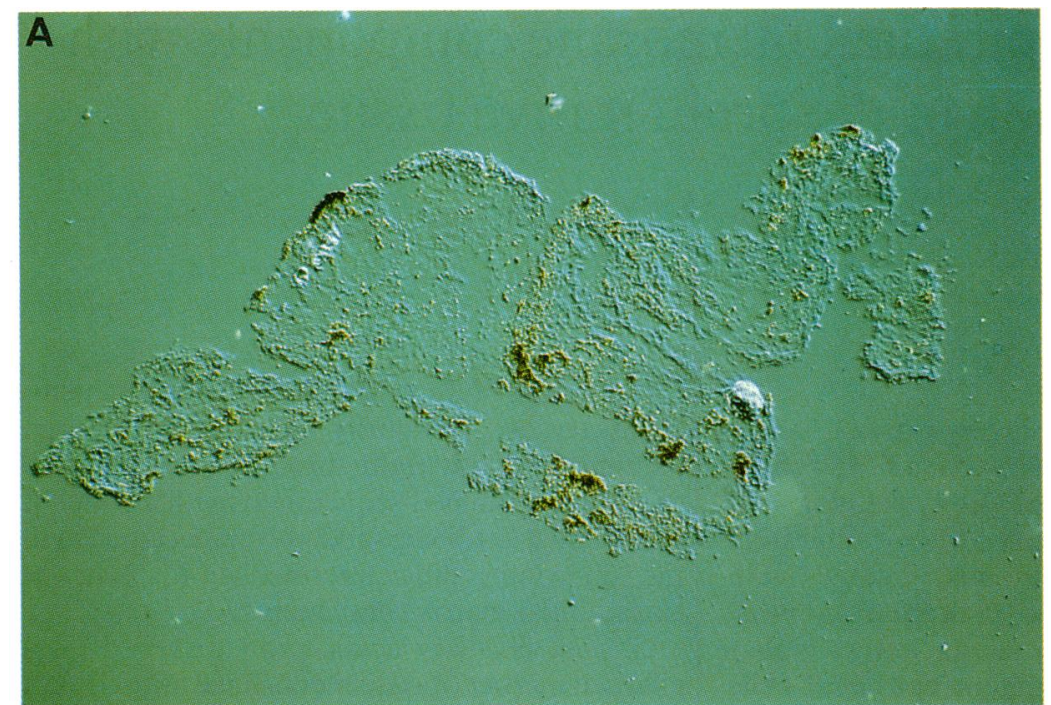

Fig $1 A$

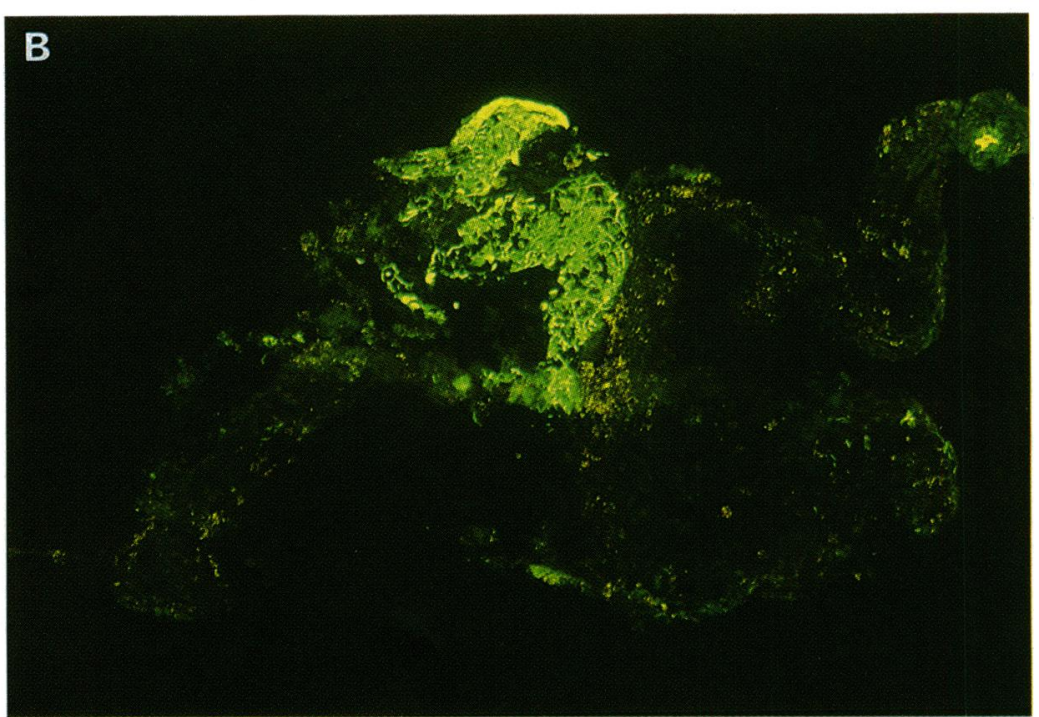

Fig $1 B$

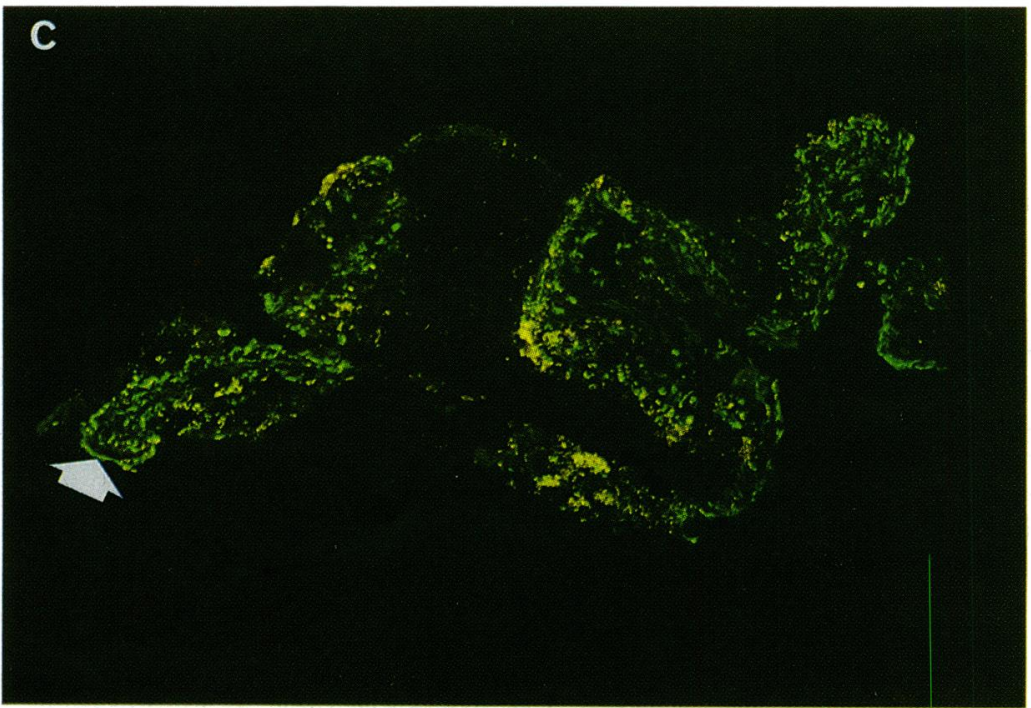

Fig $1 C$

Figure 1: (A) Differential interference contrast micrograph and $(B)$ and $(C)$ epifluorescence micrographs of serial sections from an early epiretinal membrane. $(A)$ The general morphology of the tissue can be seen, including deposits of brown melanin granules. (B) Immunofluorescence stain for GFAP. A large focus of glial cells is present in the centre of the section. $(C)$

Immunofluorescence stain for cytokeratin. Many cytokeratin-positive cells are present in the non-glial part of the tissue, including a layer of cells $($ arrow $)$. $($ All $\times 60)$.
TABLE I Cellular components of epiretinal membranes (ERMs)

\begin{tabular}{lcc}
\hline ERM & $\begin{array}{l}\text { GFAP-positive } \\
\text { cells }\end{array}$ & $\begin{array}{l}\text { Cytokeratin-positive } \\
\text { cells }\end{array}$ \\
\hline no. & (A) Early membranes ( $\leqslant 4$ months) \\
1 & $20 \%$ & \\
2 & $15 \%$ & $30 \%$ \\
3 & $20 \%$ & $40 \%$ \\
4 & $20 \%$ & $40 \%$ \\
5 & $10 \%$ & $15 \%$ \\
6 & $10 \%$ & $15 \%$ \\
7 & $5 \%$ & $30 \%$ \\
$\star 8$ & $20 \%$ & $40 \%$ \\
9 & $10 \%$ & $5 \%$ \\
& & $30 \%$ \\
(B) Late membranes & \\
10 & $60 \%$ & \\
11 & $30 \%$ & $20 \%$ \\
12 & $20 \%$ & $40 \%$ \\
13 & $5 \%$ & $10 \%$ \\
14 & $0 \%$ & $20 \%$ \\
15 & $20 \%$ & $5 \%$ \\
16 & $30 \%$ & $10 \%$ \\
$\star 17$ & $15 \%$ & $0 \%$ \\
18 & $15 \%$ & $5 \%$ \\
19 & $40 \%$ & $0 \%$ \\
20 & $10 \%$ & $0 \%$ \\
\hline
\end{tabular}

GFAP $=$ glial fibrillary acidic protein

$\star$ Vascular component in membrane.

\section{Results}

CELLULAR COMPONENTS OF ERMS

GFAP-positive cells were observed in 19 of the 20 ERMs (Table I, Figs 1 to 3). Although late membranes appeared to contain proportionally more glial cells (22\%) than early ERMs (14\%), there was no significant difference between the two groups. The cells varied in shape. They included stellate and rounded cells, and were usually arranged in foci or layers (layers or foci were present in eight early and nine late ERMs), only occasionally being seen as isolated cells at the edge of the tissue or on strips of inner limiting lamina (ILL) of the retina (Figs 1 to 3 ).

Seventeen of the ERMs contained cytokeratinpositive cells (Table I, Figs 1, 4, 5). All the early membranes had an epithelial cell component (with an average of $27 \%$ RPE cells each), while eight of the 11 late membranes incorporated RPE cells (average content $11 \%$ ), and the difference was significant $(p<0 \cdot 02)$. Eight early and five late ERMs contained rounded or cuboidal RPE cells arranged in foci or layers (Table I, Figs. 1, 4, 5), while all of the early and four of the late specimens contained elongated, sometimes plump or spindle-shaped ('fibroblastlike') cytokeratin-positive cells set in fibrous tissue (Figs. 1, 4).

GFAP- and cytokeratin-negative cells were present in all ERMs (Figs. 1 to 5), but no significant difference was found between the proportions of these cells in early $(59 \%)$ and late (66\%) specimens. Apart from vascular endothelial cells (two ERMs, Table I), the non-glial, non-epithelial cells comprised inflammatory and elongated, fibroblastic ('true fibroblast') GFAPand cytokeratin-negative cells. These cells generally were distributed in the fibrous component of the membranes.

EXTRACELLULAR COMPONENTS

Collagen types I, III, and IV were present in all specimens (Table II, Figs 2 to 5). while 14 ERMs were immunoreactive for collagen type II. 

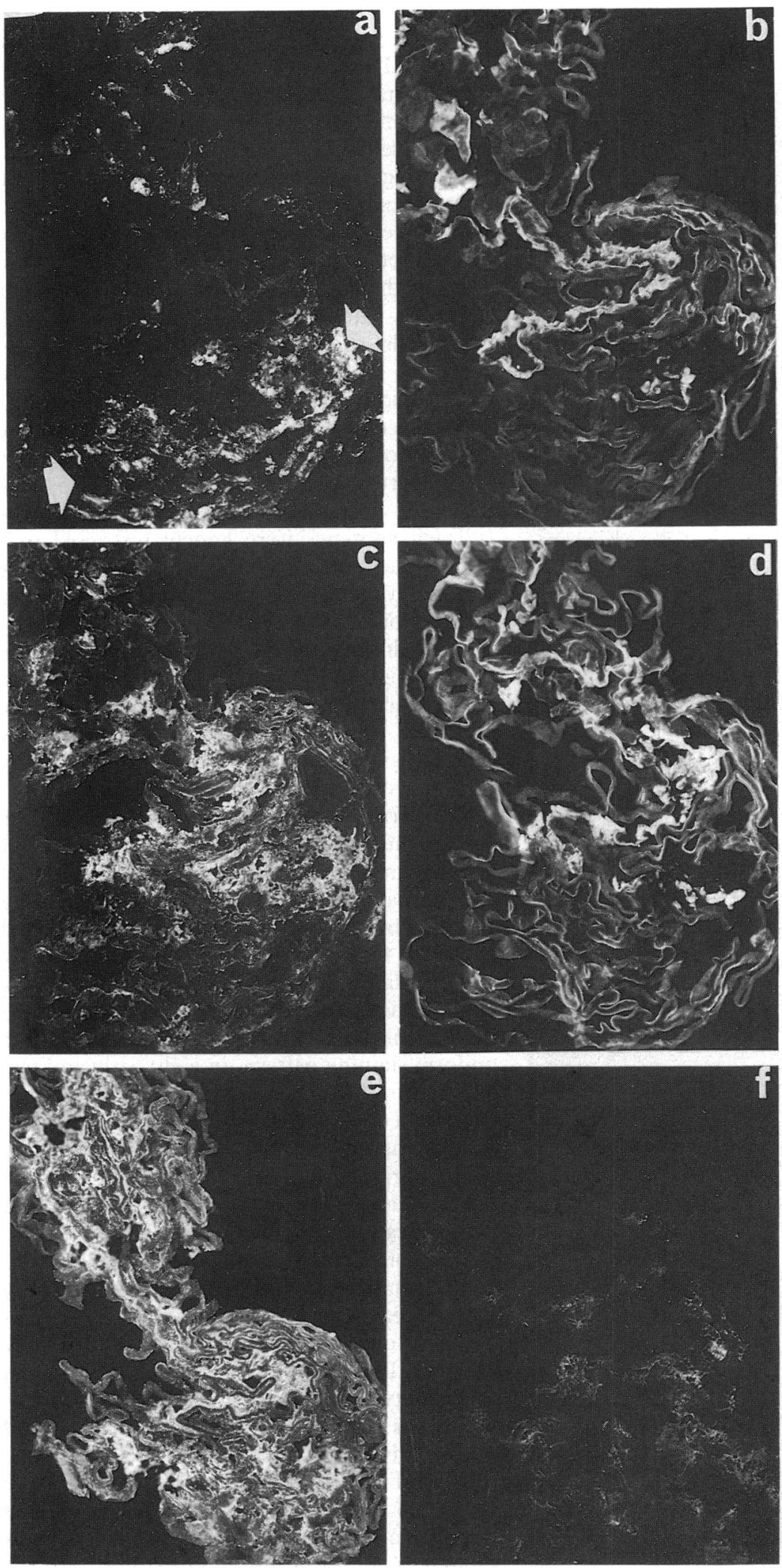

Figure 2: Epifluorescence micrographs of serial sections from a late ERM.

(a) Immunostaining for GFAP reveals glial cells (arrows). (b), (c), and (d). Immunolabelling for collagen types I, II and IV respectively show that much of the specimen consists of thick, ILL-like material (seen by type IV collagen immunoreactivity in d). The ILL and glial components are associated with the collagen subtypes. $(e)$ and $(f)$ : Immunostained for fibronectin and laminin respectively. Fibronectin is abundant in the specimen while laminin is a relatively minor element of the tissue. $($ All $\times 165)$.

Although early ERMs appeared to contain more collagen type IV than late membranes, no statistical difference could be demonstrated between the proportion of any of the individual collagen types in the two groups. However, types I and III were the most abundant forms of
TABLE II Extracellular components of epiretinal membranes (ERMs)

\begin{tabular}{|c|c|c|c|c|c|c|}
\hline $\begin{array}{l}\text { ERM } \\
\text { no. }\end{array}$ & I & II & III & IV & FN & LM \\
\hline \multicolumn{7}{|c|}{ (A) Early membranes ( $\leqslant 4$ months) } \\
\hline 1 & $60 \%$ & $5 \%$ & $60 \%$ & $45 \%$ & $95 \%$ & $0 \%$ \\
\hline 2 & $80 \%$ & $0 \%$ & $70 \%$ & $55 \%$ & $75 \%$ & $0 \%$ \\
\hline 3 & $60 \%$ & $5 \%$ & $60 \%$ & $45 \%$ & $70 \%$ & $5 \%$ \\
\hline 4 & $80 \%$ & $15 \%$ & $80 \%$ & $80 \%$ & $85 \%$ & $15 \%$ \\
\hline 5 & $70 \%$ & $10 \%$ & $70 \%$ & $65 \%$ & $85 \%$ & $5 \%$ \\
\hline *6 & $60 \%$ & $5 \%$ & $65 \%$ & $90 \%$ & $95 \%$ & $10 \%$ \\
\hline 7 & $85 \%$ & $20 \%$ & $85 \%$ & $65 \%$ & $80 \%$ & $10 \%$ \\
\hline 8 & $80 \%$ & $15 \%$ & $75 \%$ & $70 \%$ & $90 \%$ & $20 \%$ \\
\hline$\star 9$ & $55 \%$ & $0 \%$ & $55 \%$ & $75 \%$ & $65 \%$ & $5 \%$ \\
\hline \multicolumn{7}{|c|}{ (B) Late membranes ( $>4$ months) } \\
\hline 10 & $35 \%$ & $0 \%$ & $35 \%$ & $25 \%$ & $25 \%$ & $0 \%$ \\
\hline$\star 11$ & $30 \%$ & $30 \%$ & $25 \%$ & $60 \%$ & $55 \%$ & $30 \%$ \\
\hline 12 & $80 \%$ & $5 \%$ & $80 \%$ & $70 \%$ & $90 \%$ & $0 \%$ \\
\hline 13 & $90 \%$ & $20 \%$ & $90 \%$ & $55 \%$ & $65 \%$ & $10 \%$ \\
\hline 14 & $70 \%$ & $0 \%$ & $70 \%$ & $55 \%$ & $50 \%$ & $10 \%$ \\
\hline 15 & $80 \%$ & $0 \%$ & $80 \%$ & $75 \%$ & $95 \%$ & $5 \%$ \\
\hline 16 & $70 \%$ & $5 \%$ & $70 \%$ & $50 \%$ & $60 \%$ & $10 \%$ \\
\hline 17 & $70 \%$ & $10 \%$ & $70 \%$ & $25 \%$ & $65 \%$ & $5 \%$ \\
\hline 18 & $85 \%$ & $0 \%$ & $85 \%$ & $65 \%$ & $15 \%$ & $5 \%$ \\
\hline 19 & $60 \%$ & $5 \%$ & $60 \%$ & $25 \%$ & $55 \%$ & $0 \%$ \\
\hline 20 & $90 \%$ & $15 \%$ & $00 \%$ & $20 \%$ & $90 \%$ & $0 \%$ \\
\hline
\end{tabular}

I to IV=collagen types I to IV.

$\mathbf{F N}=$ fibronectin

LM = laminin.

* Membranes with abundant inner limiting lamina.

collagen in the specimens, while collagen type II was a minor component ERMs. (The content of type IV collagen was intermediate between types I/III and II.) The distributions of collagen types I and III were similar and showed confluent areas of immunoreactivity which in some cases occupied almost the entire specimen (Table II, Fig 5). Type II collagen tended to represent small isolated areas in the specimens, frequently adjacent to the specimen edge or ILL (Fig 2c). Type IV $^{\prime}$ :ollagen also formed confluent areas and was only found in association with collagen types I and III or ILL (Fig 2, 4).

Although all the specimens contained fibronectin (Table II, Figs 2, 5), the glycoprotein was more abundant in early than late ERMs, and the difference was significant $(p<0 \cdot 038)$. Fibronectin was distributed in focal patches or evenly throughout large areas of the tissues.

Laminin was present in 14 of the 20 ERMs, but was a minor component in the tissue (Table II, Figs 2, 5). Although all but two early membranes contained laminin while four late specimens lacked the glycoprotein, no significant difference was found between the overall laminin content of early and late groups. The ILL showed the most consistent laminin immunolabelling, though this tended to be patchy. Laminin was sometimes distributed as small isolated foci adjacent to cells in collagen or around ILL (Fig 2).

RELATIONSHIP BETWEEN CELLULAR AND EXTRACELLULAR ERM COMPONENTS

GFAP-positive cells showed variable immunoreactivity for extracellular matrix components (within and between ERMs - Fig 2, 3). In four ERMs (two early and two late) glia showed uniform immunostaining for collagen subtypes I, III, and IV (Figs 3a, b). However, commonest staining pattern for collagen I, III, and IV in glia was of some collagen-positive cells in a predominantly collagen-negative glial component; approximately half (four early and four late) the 

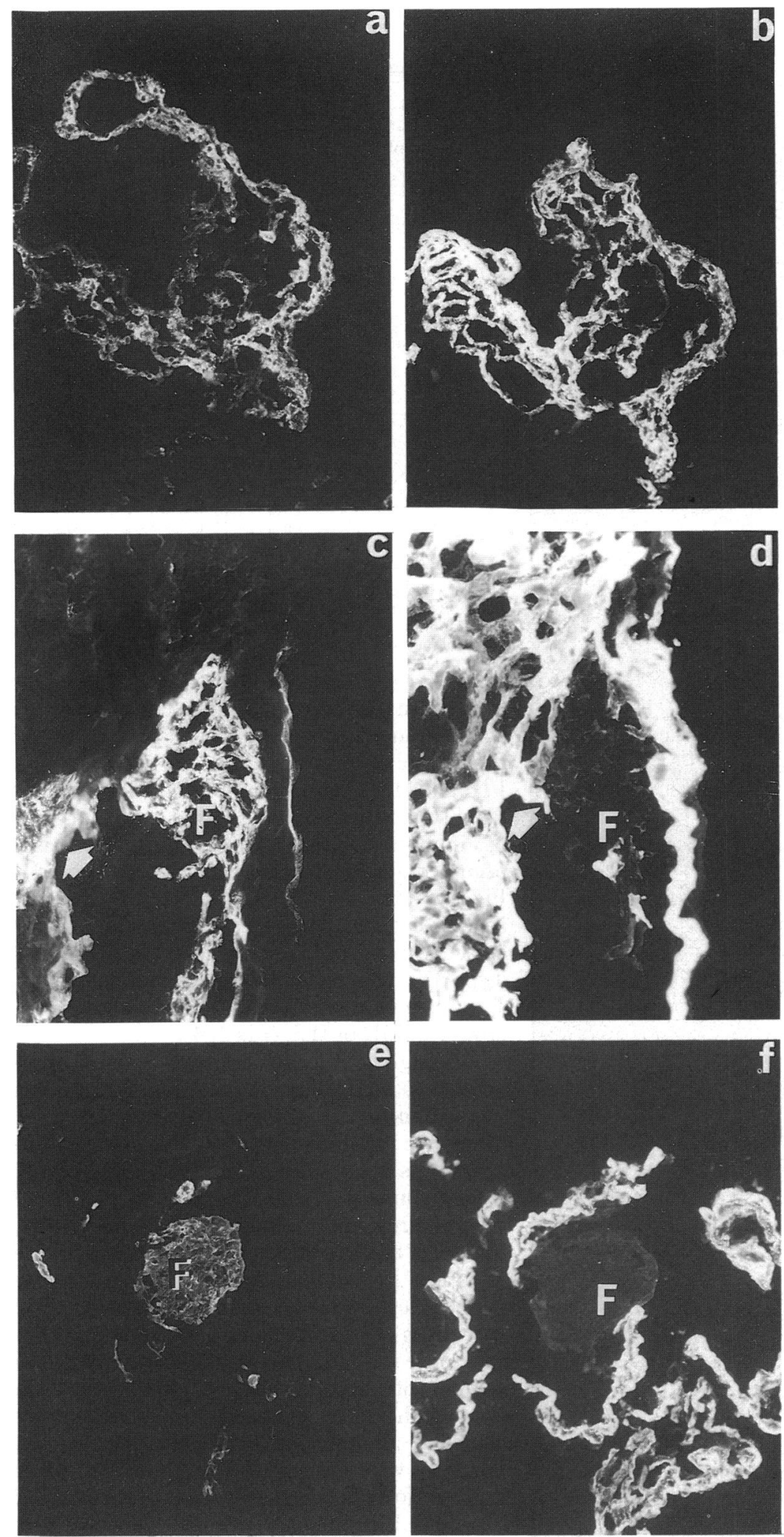

Figure 3: Epifluorescence micrographs of epiretinal membranes stained with the immunofluorescence technique. (a) An early ERM stained for GFAP shows a layer of glial cells which are intensely immunoreactive for $(b)$ collagen type III $(\times 125)$. (c) Another early membrane stained for GFAP contains a focus $(F)$ and a layer (arrow) of glial cells. (d) $A$ sequential section of the membrane shown in (c) has been labelled for collagen type I to demonstrate that the glial layer (arrow) stains for the collagen subtype, while the glial focus $(F)$ is predominantly collagen type I-negative $(\times 250)$. $(e)$ and $(f)$ : Sequential sections from a late ERM stained for $(e) G F A P$ and $(f)$ collagen type III. A focus of glial cells $(F)$ does not immunoreact for collagen type III, while the surrounding non-glial shows intense labelling ( $\times$ 125).

membranes displayed this patchy pattern. In two specimens glial layers immunolabelled for collagen types I, III, and IV while glial foci were largely collagen-negative (Fig $3 c$, d). The glial cells in the remaining specimens (two early, three late) did not immunoreact for collagen types I, III, or IV (Fig 3e, f). Collagen type II immunostaining correlated with a few glial cells in one early and three late ERMs, being most pronounced where glia were adjacent to ILL strips (Fig 2). Fibronectin was associated with glial cells in 15 membranes (Fig 2). Fibronectinpositive cells were uniformly distributed in the glial component of six early and three late ERMs, while in the rest of the specimens the glial cells displayed patchy staining for the glycoprotein. Glial cells showed patchy laminin immunoreactivity in three early and four late ERMs, often adjacent to ILL (Fig 2).

Rounded or cuboidal RPE cells in all but one ERM showed uniform immunoreactivity for collagen types I, III, and IV (Fig 4, 5), the exception being a late membrane in which the collagen subtypes were largely restricted to a layer round an RPE cell focus (Fig 4e, f). Patchy collagen type II staining coincided with cuboidal RPE in four early and three late ERMs. Fibronectin colocalised with all cuboidal RPE in the ERMs (Fig 5) and was uniformly distributed in the cuboidal RPE of seven early and one late specimen. Patchy laminin immunoreactivity coincided with cuboidal RPE in five of the early and three of the late specimens.

Cytokeratin-positive fibroblast-like cells showed uniform colocalisation of collagen types I and III and, in all but two late ERMs which showed patchy labelling, collagen type IV (Fig 4). By contrast, collagen type II was associated only with fibroblast-like RPE cells in four early and two late specimens, and then chiefly in a patchy distribution. All fibroblast-like RPE showed fibronectin immunoreactivity, with a uniform staining pattern, in eight early and two late ERMs. Fibroblast-like RPE showed either patchy (in one early and two late membranes) or no labelling for laminin.

Cytokeratin-negative fibroblasts showed uniform colabelling for collagen types I, III, and IV in all early ERMs and six late ERMs (Fig 5), while in four late membranes these cells displayed uniform staining for collagen I and III but patchy immunoreactivity for collagen IV. The fibroblasts in one late ERM demonstrated patchy collagen I, III, and IV labelling. Uniform collagen type II staining was associated with fibroblasts in only one (early) specimen and patchy labelling in two early and three late ERMs. The fibroblasts in all ERMs were associated with fibronectin, and the fibroblasts in eight early together with five late specimens showed a uniform immunoreactivity to the glycoprotein (Fig 5). Laminin was associated with the fibroblasts of none of the early and three of the late ERMs (in a patchy distribution).

\section{Discussion}

Our semiquantitative immunohistochemical study of PVR membranes supports the concept that glial cells persist in longstanding ERMs. ${ }^{3}$ ERMs also could contain glial elements avulsed from the retina during surgical removal. ${ }^{610}$ However, surgically excised membranes and ERMs 'in situ' (that is, in enucleated globes) 

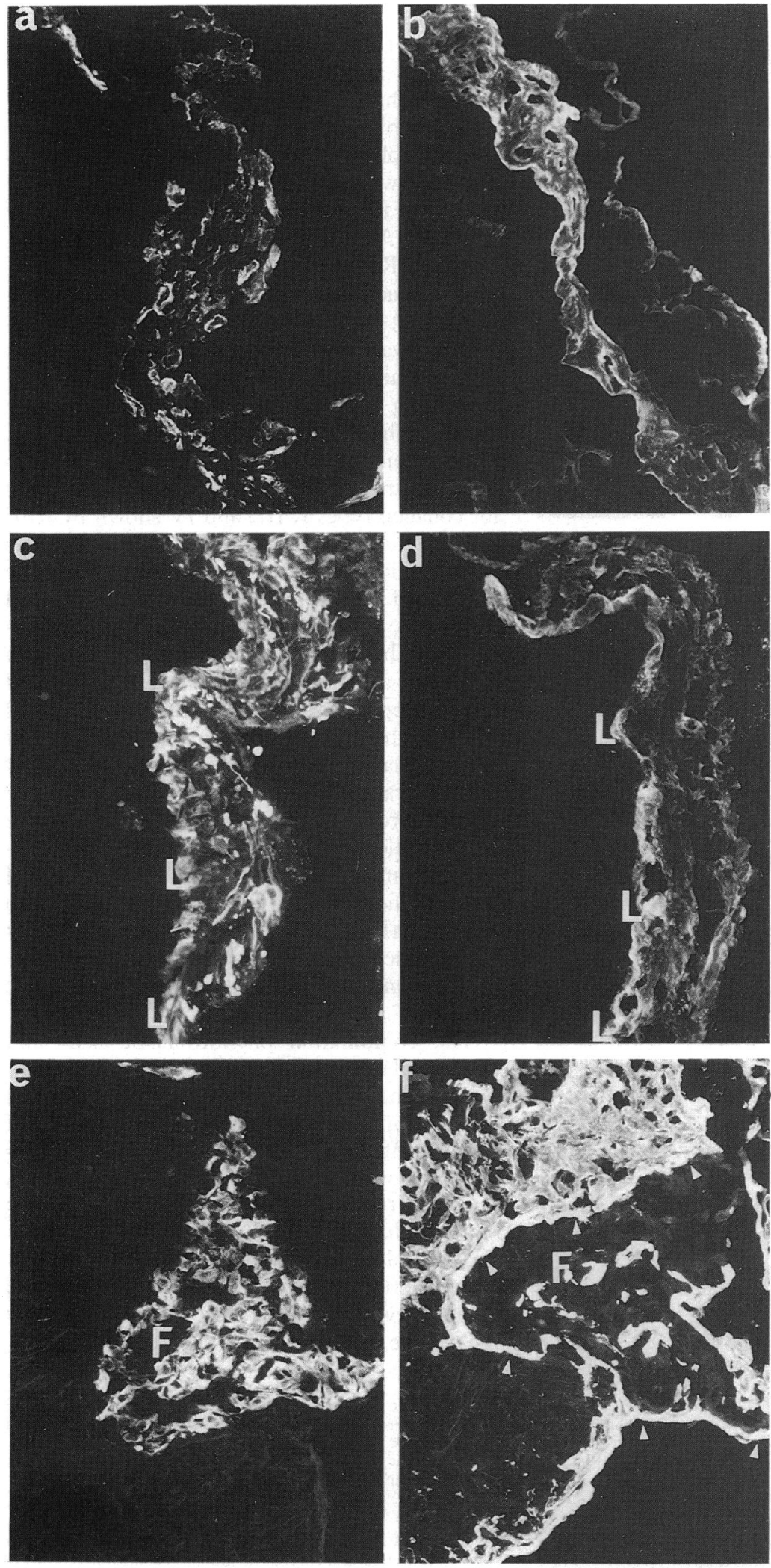

Figure 4: Epifluorescence micrographs of ERMs stained with the immunofluorescene method. (a) An early membrane stained for cytokeratin contains abundant epithelial cells, while $(b) a$ serial section shows the epithelial cells are associated with collagen type I immunoreactivity ( $\times$ $330)$. (c) and (d): Serial sections of an early ERM stained for (c) cytokeratin to reveal a layer of cuboidal epithelial cells $(L)$ adjacent to fibrous tissue containing numerous elongated and plump epithelia. The serial section (d) has been stained for collagen type IV to show that both the layered, cuboidal $(L)$ and fibroblast-like epithelial cells immunoreact for the collagen subtype $(x 330)$. (e) A late membrane, stained for cytokeratin, contains a focus of RPE cells $(F)$ which shows immunoreactivity for collagen type $I(f)$ is chiefly restricted to a layer (arrowheads) around the $R P E$ focus $(F ; \times 330)$.

have similar distributions of GFAP-positive cells. ${ }^{6}$ Nevertheless, the finding of a slightly larger proportion of glial cells in late ERMs than in early membranes is most likely due to a decline in other cell numbers and probably does not represent a time-dependant increase in total glial cells.

Conversely, late ERMs contained relatively fewer cytokeratin-positive cells than early ERMs. This finding was unexpected, since previous investigations revealed aggregated RPE in late as well as early ERMs'3 and developing PVR membranes accrue S100 positive cells." However, $\mathrm{S} 100$ is present in a variety of cells ${ }^{1213}$ whereas cytokeratins are thought to be specific for epithelial cells. Moreover, cytokeratinpositive fibroblast-like cells are present in the fibrous component of the ERMs ${ }^{78}$ and the present study shows that these fibroblast-like RPE are present in all the early but only a few of the late membranes. Therefore the fibroblast-like subpopulation of RPE may be specifically lost in aging, though there is also some decline in aggregated RPE.

The age related decline in RPE may in part explain the differences between two previous studies of cytokeratin-positive cells in ERMs. An investigation at this laboratory ${ }^{7}$ found that not all PVR membranes contained RPE, whereas Jerdan and colleagues ${ }^{14}$ found RPE in all their PVR specimens. If the specimens examined by Jerdan and coworkers were of a clinically shorter duration than those of our earlier study the differences might have been expected, since in this investigation all the early ERMs contained RPE cells, and cytokeratin-positive cells were absent only from some longstanding PVR membranes. Although we did restrict the specimens in our earlier study to predominantly cellular ERMs, ${ }^{7}$ we did not attempt to group them according to clinical duration.

The late ERMs of this investigation contained approximately the same percentage of GFAPand cytokeratin-negative cells as did early membranes. Previous investigations revealed that late ERMs tended to contain relatively more inflammatory cells than early specimens, while cells with the morphological features of fibroblasts underwent lipoidal degeneration. ${ }^{3}$ The fibroblastic cells, which probably included fibroblast-like RPE, may have been deprived of nutritional requirements following their 'entombment' in extracellular material.

Our findings concerning the extracellular content of ERMs generally are in keeping with previous immunochemical studies of PVR specimens. ${ }^{310^{114-16}}$ Thus the ERMs usually contain abundant collagen types I and III and fibronectin, while, except in association with fragments of ILL, laminin and collagen II/IV immunoreactivity is more variable. No difference in the proportions of any collagen subtype or laminin is apparent between the two 'age' groups, though some correlation between ERM duration and collagen subtype might be expected, because mature dermal wounds contain more collagen type I than type III. The persistence of type III collagen in late ERMs may indicate protracted synthesis of extracellular matrix components within the epiretinal tissue. However, late ERMs do contain less fibronectin than early specimens. A time dependant change in fibronectin is also seen in healing wounds, where the glycoprotein has important adhesive 

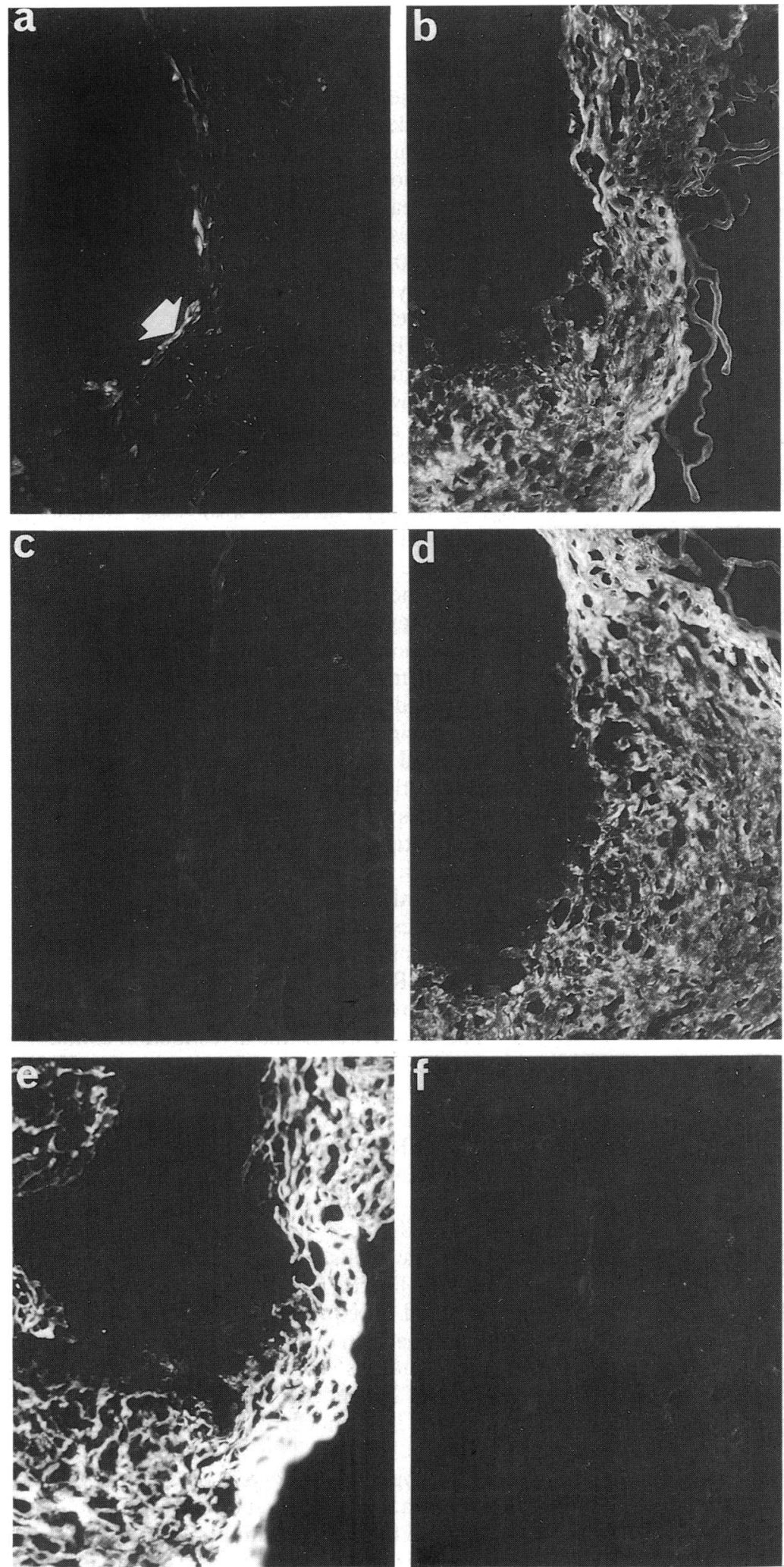

Figure 5: Epifluorescence micrographs of serial sections of a late ERM stained with the immunofluorescence technique. (a) Section stained for cytokeratins reveals a thin layer of epithelial cells on the surface of the specimen (arrow), while the rest of the specimen contains cytokeratin-negative cells. $(b),(c),(d),(e)$, and $(f)$ : Sections labelled for collagen types $I, I I$, and III, fibronectin, and laminin respectively. The tissue shows uniform immunostaining for collagen types I and III and fibronectin, but no collagen type II or laminin reactivity. (All $\times$ 165).
CORRELATION BETWEEN CELLULAR AND EXTRACELLULAR ERM COMPONENTS

A recent immunohistochemical investigation indicates that collagen in PVR membranes is not produced by glial cells. ${ }^{11}$ However, glial cells can produce collagen in vitro and in the vitreous of rabbits, ${ }^{21}$ while non-vitreous collagen may be found in ERMs whose cellular content is glia in origin. ${ }^{22} 23$ Although the synthetic activities of cells in ERMs cannot be inferred from their immunoreactivity to various extracellular matrix constituents alone, our observation of glial cells showing variable immunoreactivity for extracellular matrix components in PVR specimens is in keeping with the idea that in some circumstances epiretinal glia synthesises collagens and glycoproteins.

By contrast, the consistent immunoreactivity for collagen types I, III, and IV shown by RPE cells, including fibroblast-like forms, provides further evidence for the concept that part of the collagen of ERiris - at least in PVR - is produced by RPE cells. ${ }^{11+2+}$ Moreover, cytokeratinnegative fibroblast-like cells in ERMs also show a particular association with collagen types I and III, in keeping with the view that, as in dermal wounds, the fibroblastic cells are synthesisers of extracellular matrix. Thus the findings suggest that several cell types are responsible for the ERM fibrous component. Nevertheless, the colocalisation of extracellular material constituents and ERM cells may be due to several factors - including the migration of the cells into a pre-existing scaffold. Cellular migration may explain the variable relationship between basement membrane components and fibroblastic cells.

The combination of fibroblastic cells and extracellular material provides a fibrous ERM portion which often lies adjacent to a layer of glial cells, or sometimes RPE cells, and gives many of the ERMs a laminated architecture. This organisation of membrane components underlies the care required to ensure all lamellae are removed during ERM 'peeling', ${ }^{20}$ since a surgical cleavage plane may form between the layers of epiretinal tissue. Moreover, as the ERM matures, planes between lamellae may be accentuated by the decline in fibronectin.

We thank Mr C Canning, Mr R Cooling, Mr Z Gregor, Mr P Leaver, and Professor D McLeod, who provided many of surgical specimens. Dr D Minassian assisted with the statistical analyses. Our work has been funded by the Wellcome Trust (grant no. 17095/1.4R) and Fight for Sight.

1 Kampik A, Kenyon KR, Michels RG, Green WR, de la Cruz Z. Epiretinal and vitreous membranes: comparative study of 56 cases. Arch Ophthalmol 1981; 99: 1445-54.

2 Constable IJ, Tolentino FI, Donovan RH, Schepens CL. Clinico-pathologic correlation of vitreous membranes. In: Pruett RD, Regan DJ, eds. Retinal congress. New York: Appleton-Century-Crofts, 1974; 245-57.

3 Hiscott PS, Grierson I, McLeod D. Natural history of fibrocellular epiretinal membranes: a quantitative, autoOphthalmol 1985; 69: 810-23.

4 Peacock EE. Inflammation and the cellular response to injury. Wound repair. Philadelphia: Saunders, 1984: 1-14.

5 The Retina Society Terminology Committee. The classification of retinal detachment with proliferative vitreoretinopathy. Ophthalmology 1983; 90: 121-5.

6 Hiscott PS, Grierson I, Trombetta CJ, Rahi AH, Marshall J, McLeod D. Retinal and epiretinal glia-an immunohistochemical study. BrF Ophthalmol 1984; 68: 698-707.

7 Hiscott PS, Grierson I, McLeod D. Retinal pigment epithelia cells in epiretinal membranes: an immunohistochemical study. Brf Ophthalmol 1984; 68: 708-15. fibronectin disappears ${ }^{17-19}$ The scar matures bioadhesive fibronectin with aging may be a factor in explaining why long-standing ERMs are more easily dissected than early membranes. ${ }^{20}$ 
8 McKechnie NM, Boulton M, Robey H, Savage FJ, Grierson I. The cytoskeletal elements of human retinal pigment epithelium: in vitro and in vivo. $\mathcal{F}$ Cell Sci 1988; 91: 30312 .

9 Newsome DA, Pfeffer BA, Hewitt AT, Robey PG, Hassell JR. Detection of extracellular matrix molecules synthesized in vitro by monkey and human retinal pigment epithelium: influence of donar age and multiple passages. Exp Eye Res 1988; 46: 305-21.

10 Sramek SJ, Wallow IH, Stevens TS, Nork TM. Immunostaining of preretinal membranes for actin, fibronectin and
glial fibrillary acidic protein. Ophthalmology 1989; 96: 835glial

11 Ihme A, Tavakolian U, Pham-Duy TH, Wollensak J. Characterisation of cell types in vitrectomy specimens by immunohistochemical methods. In: Heimann $\mathbf{K}$, Wiedemann P, eds. Proliferative Vitreoretinopathy. Heidleberg: Kaden, 1989: 73-7.

12 Crocker J, Jenkins R, Campbell J, Fuggle WJ, Shah VM. Immunohistochemical demonstration of S-100 protein in salivary gland neoplasms. F Pathol 1985; 146: 115-21.

13 Dwarakanath S, Lee AKC, Delellis RA, Silvermann ML Frasca L, Wolfe HJ. S-100 protein positivity in breast Frasca L, Wolfe $\mathrm{HJ}$. S-100 protein positivity in breast chemistry. Hum Pathol 1987; 18: 1144-8.

14 Jerdan JA, Pepose JS, Michels RG, Hayashi H, de Bustros S, Sebag M, Glaser BM. Proliferative vitreoretinopathy membranes, an immunohistochemical study. Ophthalmology 1989; 96: 801-10.
15 Scheiffarth OF, Kampik A, Gunther H, von der Mark K. Proteins of the extracellular matrix in vitreoretinal membranes. Graefes Arch Clin Exp Ophthalmol 1988; 226: 357-61.

16 Scheiffarth OF, Kampik A, Gunther-Koszka H, von der Mark $\mathrm{K}$. Collagens, fibronectin and laminin in proliferative vitreoretinopathy. In: Heimann $\mathrm{K}$, Wiedemann $\mathrm{P}$, eds Proliferative Vitreoretinopathy. Heidleberg: Kaden, 1989: 134-8.

17 Kurkinen M, Vaheri A, Roberts PJ, Stenman S. Sequential appearance of fibronectin and collagen in experimental appearance of fibronectin and collagen in

18 Yamada KM, Yamada SS, Pastan I. The major cell surface glycoprotein of chick embryo fibroblasts is an agglutinin Proc Natl Acad Sci USA 1975; 72: 3158-62.

9 D'Ardenne AJ, McGee JO'D. Fibronectin in disease. $\mathcal{F}$ Pathol 1984; 142: 235-51.

20 McLeod D, Hiscott PS, Grierson I. Age-related cellular proliferation at the vitreoretinal juncture. Eye 1987; 1: 26381 .

21 Burke JM, Kower HS. Collagen synthesis by rabbit neural retina in vitro and in vivo. Exp Eye Res 1980; 31: 213-26.

22 Kenyon KR, Pederson JE, Green WR, Maumenee AE Fibroglial proliferation in pars planitis. Trans Ophthalmol Fibroglial proliferation in

23 Rentsch FJ. The ultrastructure of preretinal macular fibrosis. Graefes Arch Clin Exp Ophthalmol 1977; 203: 321-37.

24 Machemer R, van Horn D, Aaberg TM. Pigment epithelial proliferation in human retinal detachment with massive periretinal proliferation. Am f Ophthalmol 1978; 85: 181-91. 